\title{
Study on the Strategic Transformation of Enterprise Management based on Economic Globalization
}

\author{
Shuhua Nan, Yuwei Wang \\ Business Administration Department, Gongqing College of Nanchang University, Gongqing City, \\ Jiangxi Province, 332020, China
}

Keywords: Economic Globalization; Crisis; Enterprise Management; Strategic Transformation

\begin{abstract}
Whether we can effectively prevent and respond to the crisis under the background of economic globalization will directly affect the main participants in economic globalization. It is also related to the sustainable development and economic security of China's economy and society. Therefore, it is necessary to understand in time the types of crises that enterprises may encounter under the background of economic globalization, to deeply analyze the internal mechanism of various new types of crises, and to take appropriate effective measures to manage them. Based on the author's learning and practical experience, this paper first analyzed the nature and reasons of enterprise transformation, and then discussed the driving effect of economic globalization on the strategic transformation of enterprise management. Finally, the paper put forward the strategies of business strategy transformation under the background of economic globalization.
\end{abstract}

\section{Introduction}

China's entry into WTO marks an opportunity for Chinese enterprises to integrate into economic globalization. More and more enterprises actively participate in economic globalization, and at the same time, they begin to participate in economic globalization by means of foreign direct investment. At the same time, enterprises encounter more and more crisis forms, and the degree of influence is more and more deep. Therefore, the strategic transformation of enterprises is the fundamental overall transformation from the operation mode to the organizational mode. It is also a necessary strategic channel for enterprises to enhance their market competitiveness and adapt themselves to the process of economic globalization.

\section{The Essence and Reason of Enterprise Transformation}

The essence of enterprise transformation is the active and thorough transformation and reform in order to achieve the management goal. First of all, it takes the enterprise's own development as the starting point, carries on the innovation and the reconstruction to the enterprise's strategic goal, since then all the activities must obey the strategic goal. Secondly, the strategic transformation of enterprise management and development is to adapt to the trend of the globalization of the external environment, to actively enhance its own competitiveness, so as to achieve sustainable development in the current market. Since the reform of strategic transformation is a fundamental change, the core of the transformation is innovation of knowledge, technology and management, so the transformation is innovative.

There are two reasons for the strategic transformation of business development - One is driven by the internal reasons of the enterprise, and the other is the help of the external environment. The internal reason is that the core competence of the enterprise itself is deficient and can not satisfy its role in the market competition. In order to widen the profit and develop new way, the enterprise 
starts to drive the strategic transformation from the reorganization of the organization, in order to cope with the market change of the industry pattern of economic globalization and strengthen the enterprise activity. Therefore, only by establishing and maintaining this core ability, can we improve the competitive ability of enterprises and enhance their competitive advantage in the market. The external factor is that the changes in the external environment lead to a slowdown in the development of the enterprise. The core competence of the enterprise is no longer sufficient to adapt to other social elements, including politics, economy, social culture, science and technology, etc. So we have to make a transformation to adapt to the new environment development, to acquire new growth capacity.

\section{Driving Effect of Economic Globalization on Enterprise Management Strategy Transformation}

The trend of economic globalization is both an opportunity and a challenge for Chinese enterprises in economic development. In the global market of economic globalization, enterprises have to make transformation and reform if they want to seek their own development and adapt to the process of globalization. Economic globalization brings enterprises a more severe competitive situation. Because it is a comprehensive and open system, domestic and foreign enterprises can exchange needs in an open system, of course, this will create a survival of the fittest situation competition will be unprecedented fierce. At present, the world economic globalization is facing two trends: first, the enterprise competition under the economic globalization has already exceeded the enterprise itself, but expanded to the competition of the economic strength among the countries and regions, the scope of the competition is wider. Second, the globalization of trade, capital, information and technology has allowed the free flow of resources around the world with more competition.

Economic globalization has some powerful driving effects on the strategic transformation of enterprise management and development, which are reflected in the following aspects: First, transnational capital cooperation. Not only China and Western developed countries, the world is in a wave of transnational cooperation. China's low-cost resources and huge market make countries scramble to import capital. Under the economic globalization, developed countries provide convenient conditions for developing countries to enter the domestic market by lowering tariff barriers. In the global integration, the developed countries rely on their own strong economic strength, a large number of foreign capital flow into China. The domestic pillar industry and the national industry are manipulated by foreign parties to different degrees, which makes the development of our country's enterprises be shaky. Therefore, the entry of multinational companies not only provides financial support and advanced technology guidance to Chinese enterprises, but also brings potential major threats. Second, under the economic globalization the market expands gradually, the competitor is also increasing, so, the enterprise not only face the domestic colleague's competitor, but also must deal with the foreign competitor, which requests enterprise unceasingly enhances oneself and enhances the competitive strength. Second, under the economic globalization the market expands gradually, the competitor is also increasing, the enterprise must not only face the domestic colleague's competitor, but also must deal with the foreign competitor, this request enterprise unceasingly enhances oneself, enhances the competitive strength. Third, the international situation has a profound impact on the economy. The impact of the financial crisis has caused great distress to Chinese enterprises, which has made enterprises that were originally not strong in development face a deeper economic crisis and face such a severe trend of competition. In the economic competition between countries and regions, we should actively apply industrial policies, 
adjust the exchange rate to maintain the competitive advantage of our industries, and make great efforts to carry out the strategy of alliance and develop regional economic alliances in all regions. In this way, it not only enables the countries in the alliance region to carry on favorable economic trade, but also helps each alliance region to reach a certain scale, thus strengthening the foundation and strengthening the combat capacity to resist the challenge.

\section{The Process and Strategy of Business Strategy Transformation in the Background of Economic Globalization}

The process of business strategy transformation in the background of economic globalization. First, to establishes the decision-making system of strategic transformation to analyze and guide the transformation structure, and carries on the implementation of the specific strategy of strategic transformation according to this system. Through a comprehensive analysis for the environment, industry and internal resources of enterprises, decision-making system analyzes the changes of internal and external environment of enterprise development and the impact and influence, and then puts forward the strategic transformation action to adapt to the change of environment.It analyzes the situation of the industry in which the enterprise is located, and makes a macro analysis on the situation of the industry so as to put forward the requirements of promoting competitiveness in the course of transformation.it analyze the internal resources of the enterprise, analyze the competitive strength and resources of the enterprise to give full play to the competitive advantage, and makes up for the disadvantage and deficiency in order to promote and renew the enterprise. Second, to grasp the opportunity period of strategic transformation. Strategic transformation is a gradual process, and the change of external environment is also a subtle process, so it is particularly important for enterprises to choose the timing of material transfer. Many enterprises only realize that their own strength can not meet the competitive needs of the market or can not adapt to the changes in the market environment before starting the strategic transformation, and this is precisely the best time to delay the transformation. The strategic transformation of enterprises should be on the alert, strengthen the crisis consciousness, analyze whether the enterprise's own strength has the conditions of transformation in the opportunity period, and then take the countermeasures in time to start the transformation in the first time.

The strategy of business strategy transformation in the background of economic globalization. Improve the level of enterprise management. The sales performance can be improved by improving the sales level of the enterprise's sales personnel and improving their grasp of the market and the level of product supply and marketing. Improve the management level of enterprise managers, and do a good job in the development of the principles and policies of enterprise management and implementation of the work. To promote the joint reorganization of enterprise resources, to concentrate the core productivity of enterprises, to optimize the production mode, to reduce production costs, and to provide a solid development basis for the strategic transformation of management. In order to actively adopt new technology and talent strategy, science and technology should be the primary productive forces. In the face of the rapid development of science and technology, enterprises should actively adopt new production technology strategies, innovate production methods, and gradually enhance their own advanced productive forces with advanced scientific and technological content to improve the core competitiveness of enterprises. If an enterprise has advanced productivity, it will be able to gain absolute advantage in the market. So the promoters of advanced production technology are scientific and technological talents. Enterprises should cultivate and absorb talents with innovative spirit and advanced science and technology, improve the overall scientific and technological level and personnel quality of enterprises, and 
provide a strong human resource basis for the transformation. To vigorously develop the industrial supply chain. Supply chain is a whole function chain structure that starts from the purchase of raw materials and components to product manufacture, transportation and warehousing, and finally reaches the consumer terminal, covering the whole logistics. It consists of suppliers, manufacturers, distributors, customers and service providers. It mainly operates chains in the supply process, production and planning process, logistics process and service demand. It reflects the economic benefits of the enterprise's history, strategy and activities itself. To shapes the core values of an enterprise. The core values of enterprises are the backbone of the vigorous development of enterprises, and emphasis on the shaping of values will promote the innovation of corporate culture. Unified and powerful enterprise core values are helpful to stimulate the team combat effectiveness of the enterprise team, and thus identify with the enterprise transformation strategy and actively implement the transformation strategy.

\section{Summary}

In China, the transformation of enterprise management and development strategy should be based on China's national conditions and its own strength. Under the situation of economic globalization, in order to adapt to the changes of the environment, enterprises should improve their market competitiveness and vitality in the changes, and transform the management strategy, which plays a key role in the survival of enterprises.

\section{Acknowledgements}

Subject of Science and Technology Research Project 2017 of Jiangxi Education Department: Research on Guiding and Promoting Independent Innovation of Clothing Enterprises in Yongqing City by Science and Technology Policy. Title number: GJJ171467. Project leader: Shuhua Nan.

Project of Jiangxi Education Science Planning Education Leadership Group 2017: A Study on

the Construction and Application of the Model of Teachers' Professional Competence in Independent Colleges. Subject number: 18YB399, as a participant.

\section{References}

[1] Jin Xiaogang. On Economic Globalization and multinational Management Strategy of Chinese Enterprises[J]. Economic and Trade Practice, 2018(13):62-63.

[2] Li Juan.Analysis of International Marketing Strategy from the Perspective of Economic Globalization[J]. Commercial Economy Research, 2016(19):46-48.

[3] Xu Lifan. The New Crisis Faced by Enterprises under the background of Economic Globalization and the Way to Deal with It[J]. Enterprise economy, 2014(08):54-57.

[4]Yang Man. On the Strategic Management of Enterprises under the background of Globalization[J]. Oriental Corporate Culture, 2014(02):1+3.

[5]Zhang Hang. New ideas on Financial risk of Enterprises under the background of Economic Globalization[J]. China's foreign investment, 2014(01):63-64. 